\title{
ИНСАЙДЕРСКАЯ УГРОЗА, КАК КЛЮЧЕВАЯ ПРОБЛЕМА ОБЕСПЕЧЕНИЯ БЕЗОПАСНОСТИ ОРГАНИЗАЦИИ, И МЕТОДЫ ЗАЩИТЫ
}

\author{
(c) 2021 Глисин Алексей Федорович \\ кандидат экономических наук, \\ доцент Департамента корпоративных финансов и корпоративного управления \\ Финансовый университет при Правительстве РФ, Россия, Москва \\ Email: alglisin@gmail.com \\ (C) 2021 Мартюкова Вера Михайловна \\ финансовый факультет, ФФР18-4 \\ Финансовый университет при Правительстве РФ, Россия, Москва \\ Email: vera.martyukova@bk.ru
}

На сегодняшний день угроза со стороны инсайдеров является одной из ключевых для организаций, поэтому понимание ее природы может помочь управленцам в формировании стратегии с целью смягчения потенциальных последствий. В данной статье авторами анализируются проблемы по обнаружению инсайдерских угроз, а также существующие методы защиты от них со стороны бизнеса. Как итог, выделяются открытые проблемы по данной тематике и предлагаются направления по усовершенствованию защитных мер в соответствии с современными требованиями к кибербезопасности.

Ключевые слова: инсайдерская угроза, инсайдер, угроза, безопасность данных, кибербезопасность, инсайдерская информация, внутренняя угроза

\section{ВВЕДЕНИЕ}

Угрозы, которые инсайдеры представляют для правительственных организаций, предприятий и учреждений, по-прежнему вызывают серьезную озабоченность. Текущие исследования предоставляют однозначные доказательства, которые подчеркивают серьезность и распространенность этой угрозы в современном бизнесе. Согласно глобальному отчету за 2020 год, средняя стоимость инсайдерских угроз выросла на 31\% за последние два года до 11,45 млн. долларов, а количество инцидентов выросло на $47 \%$ [3].

Отчет 2016 года Агентства Европейского союза по кибербезопасности (ENISA) классифицировал четыре основных инсайдерских инцидента следующим образом:

- злоупотребление привилегиями (70\%),

- неправильное обращение с данными (13\%), использование не одобренного оборудования (10\%) и т.д. [1]

Согласно отчету ENISA об инсайдерских угрозах за 2018 год, 27\% инцидентов с нарушением данных были вызваны человеческими факторами или небрежностью, а фишинг, согласно исследованию, является основной проблемой в случае непреднамеренных внутренних угроз
(67\%). Слабые или повторно используемые пароли (56\%), разблокированные устройства (44\%), практика обмена паролями (44\%) и незащищенные сети Wi-Fi (32\%) также входили в список непреднамеренных внутренних угроз. Более того, в отчете указывается, что распространенность этих атак возросла до 56\% [1].

Таким образом, это указывает на необходимость предварительных мер, которые должны быть выполнены организациями для борьбы с данными угрозами.

Как правило, предприятия инвестируют в средства защиты, чтобы укрепить свою сеть от внешних вредоносных атак. Однако инсайдеры могут злоупотреблять своим авторизованным доступом к критически важным системам и в итоге красть или изменять системы данных с целью злого умысла или финансовой выгоды. Инсайдерская угроза нацелена не только на предприятия частного сектора, но и на государственные учреждения и критически важные инфраструктуры по мотивам, варьирующимся от денежной выгоды и промышленного шпионажа до преимуществ для бизнеса и саботажа. Поскольку инсайдеры имеют доступ к ценным информационным ресурсам, недоступным для посторонних, ущерб, причиненный в результате 
атак инсайдеров, может быть разрушительным.

Кроме того, эти угрозы становятся все более масштабными и изощренными; таким образом, подчеркивается критическая необходимость для организаций применять современные методы обеспечения безопасности.

Согласно недавнему опросу, 27\% от общего числа инцидентов с киберпреступлениями были совершены инсайдерами, и $30 \%$ респондентов указали, что разрушения, причиненные ими, были более серьезными, чем потери, причиненные внешними злоумышленниками [15].

\section{ПРИРОДА ИНСАЙДЕРСКИХ УГРОЗ}

Определения различных типов внутренних угроз варьируются от злоупотребления привилегиями до более широких определений, связанных с влиянием на конфиденциальность, целостность и доступность корпоративных данных. Суть этих определений описывает доверенный персонал, злоупотребляющий своими привилегиями в определенных целях, чтобы нанести ущерб корпорации. В данной работе рассматривается три типа инсайдеров: злонамеренный, скомпрометированный и неосторожный.

Злонамеренный инсайдер - специально злоупотребляет законными учетными данными, чтобы украсть информацию для финансовой или личной выгоды [16]. Например, человек может продать секретную информацию постороннему лицу. Они могут принести большую пользу конкурентам, поскольку, как правило, обладают достаточными знаниями о политике и методах обеспечения безопасности, а также об уязвимостях организации.

Скомпрометированный инсайдер - данные учетной записи которого были получены и непреднамеренно позволяют злоумышленнику получить доступ к конфиденциальной информации или ресурсам [9]. Например, злоумышленник может нацелиться на скомпрометированного инсайдера, собрав его учетные данные, а затем получить доступ к конфиденциальным активам, что может привести к краже персонально идентифицируемой информации.

Неосторожный инсайдер - человек, который совершает наиболее распространенные ошибки и, как правило, не уделяет значительного внимания методам обеспечения безопасности организации. Инсайдер, относящийся к этой категории, неосознанно раскрывает ключевые ресурсы посторонним..

Для первых двух типов, как правило, злоу- мышленник проводит атаки по-разному, в то время как для третьего типа не будет никаких преднамеренных атак.

Как правило, цели инсайдерского мошенничества могут варьироваться от кражи информационных активов и прямого хищения средств корпорации до торговли данными с целью личной выгоды. На основе мотива и цели атаки были установлены четыре типа инсайдерских угроз:

- Инсайдерское мошенничество - считается одной из наиболее распространенных форм атаки, при этом $61 \%$ компаний оценивают его как чрезвычайно распространенное в своей корпорации [8]. В большинстве случаев целью инсайдера-мошенника, является финансовая выгода. Это подчеркивает очевидную необходимость для организаций разрабатывать меры для защиты активов.

- Саботаж - обычно совершается инсайдерами, занимающими технические должности и обладающими профессиональными навыками [7]. Сюда можно отнести методы повышения привилегий и внедрение вредоносных программ для нарушения работы информационных систем. Мотивами этих атак является нанесение ущерба данным организации или конкретному лицу из-за недовольства, неудовлетворенных ожиданий или стресса.

- Кража IP-адресов - включает кражу важных данных (исходного кода или информацию о клиентах). Злоумышленники используют технические стратегии, такие как фишинговые электронные письма или сетевые переводы, к которым имеют законный доступ.

- Непреднамеренный инсайдер - человек, который имеет авторизованный доступ к данным организации и невольно наносит вред или существенно увеличивает вероятность будущего серьезного ущерба конфиденциальности активов организации.

\section{ВЕКТОРЫ И МЕТОДЫ АТАКИ}

Для предприятий крайне важно определить технологии, инструменты и методы, которые инсайдеры используют для осуществления атак. Это связано с потенциальным разрушением, которое они вызывают - примеры включают приостановку операций, потерю интеллектуальной собственности и ущерб репутации, поскольку у них есть легкий доступ к системам и больше возможностей для проникновения. Благодаря инцидентам с инсайдерскими угрозами можно выявить действия инсайдеров и, следователь- 
но, бороться с ними с помощью подходящих средств защиты.

Далее будут определены распространенные методы использования инсайдерской информации для взлома сетевой среды организации с целью получения доступа к ценным активам.

1. Атака с повышением привилегий - это метод, который предоставляет инсайдеру повышенный доступ к защищенным ресурсам [10]. Вертикальная эскалация привилегий предполагает, что человек предоставляет себе привилегии, обычно создаваемые для пользователей с более высоким доступом, что позволяет совершать несанкционированные действия по манипулированию информационной системой. Горизонтальная эскалация привилегий предполагает, что инсайдер использует предоставленный ему уровень доступа, но под личностью иного человека.

2. Атака на эксфильтрацию состоит в том, чтобы переместить конфиденциальные ресурсы из защищенной сети [12]. Методы передачи этих данных включают открытые (облачное хранилище синхронизации), туннелированные или скрытые каналы.

3. Фишинговые электронные письма, с помощью которых киберпреступник-аутсайдер может воспользоваться преимуществами инсайдера. Например, большинство организаций имеют общие адреса электронной почты для своих сотрудников. Как только злоумышленник выяснит алгоритм для адресов компаний, они смогут охватить множество пользователей.

Следовательно, эти методы, используемые инсайдерами, демонстрируют значительную изобретательность.

\section{СТРАТЕГИИ ЗАЩИТЫ}

Инсайдерская угроза представляет собой сложную проблему, и многие исследователи предлагают многоуровневый подход к защите, включающий разработку политики, различных процедур и технических средств контроля. Далее будут рассмотрены наиболее эффективные методы защиты и борьбы с риском инсайдерской угрозы.

Нетехническая мера защиты заключается в обеспечении последовательной и четкой политики безопасности для сотрудников всех уровней организации, так как инсайдеры используют любые пробелы в ней с целью нанести ущерб организации, Обычная практика, которую используют организации, заключается в том, что все сотрудники получают и подписывают копию данного документа, благодаря чему все работники получают представление о том, что ожидается от их должностных обязанностей, и четко понимают наказание за нарушение этих правил.

Первый этап защиты от инсайдерских угроз начинается еще на этапе найма. Потенциально ненадежные кандидаты могут быть выявлены на этапе подачи заявления путем проведения проверок биографических данных, таких как судимость, проблемы с кредитом и проверка полномочий. Положения должны применяться не только в отношении сотрудников, но и в отношении подрядчиков и субподрядчиков. Кроме того, если финансовая выгода является основным мотивом для инсайдера, то резкие изменения в благосостоянии сотрудника могут быть признаком потенциально вредоносной деятельности. Так, политика в отношении сообщений о деструктивном поведении сотрудника может помочь в защите от внутренней угрозы.

Еще одним методом защиты является строгий контроль доступа и политика мониторинга для привилегированных пользователей. Чтобы организация могла снизить риск инсайдерских угроз, ей следует внедрить строгие решения для шифрования, прежде чем разрешать доступ пользователям. Это связано с тем, что привилегированные пользователи имеют доступ к инструментам шифрования, которые представляют риск, поскольку они могут зашифровать ценную информацию (заявляя, что это их личная информация) и отказаться от предоставления ключа.

Другой процесс, который организации используют для смягчения внутренней угрозы - это разделение обязанностей для всех ролей, включая привилегированных пользователей, при этом для внесения изменений в систему требуется не менее двух человек. Более того, организации могут наблюдать, что их сотрудники получают доступ только к необходимым ресурсам, связанным с их должностью. Они достигают этого путем тщательной проверки повседневной деятельности сотрудников, и любая деятельность за пределами их границ может быть расценена как подозрительная.

Чтобы лучше понять соответствующую угрозу инсайдерской деятельности, необходимо учитывать три элемента. Один из таких элементов состоит из психологических факторов, связанных с этими атаками, и того, какое влияние ока- 
зывают технологии, такие как социальные сети, на атаки инсайдеров.

Например, атака вымогателей Национальной службы здравоохранения Великобритании WannaCry в 2018 году, которая частично зависела от внутренних пользователей при первоначальном заражении, подчеркивает растущую роль злоумышленных инсайдеров в кибератаках.

Психосоциальное поведение, подлежащее анализу, включает опоздания, прогулы, конфликты с коллегами или начальством, пренебрежение, недовольство, стресс на работе и эгоцентризм. Такие сотрудники могут совершать саботаж путем подмены, неправильного использования компьютерных функций при создании черного хода, выполнения несанкционированных программных сценариев в системах организации. Эта информация может быть получена в основном от коллег и сотрудников.

Таким образом, необходимо критически рассмотреть изучение человеческих и психологических факторов, связанных с внутренней угрозой. Это подчеркивает важность понимания сложного поведения людей в корпоративной среде и того, как это может способствовать выявлению подозрительной обработки данных инсайдером.

Несмотря на то, что организации должны понимать критичность инсайдерского риска, они больше озабочены внешними угрозами, поскольку враг воспринимается как находящийся за пределами бизнеса. Об этом свидетельствует отсутствие инвестиций в инсайдерскую безопасность. Например, опрос «Ponemon» показал, что из 61\% сотрудников, которые считают, что инсайдерская угроза представляет собой высокий риск, только 44\% считают, что их компания ставит ее в качестве приоритета [8]. Это подчеркивает тот факт, что организации считают себя плохо подготовленными, но при этом не мотивированы активизировать управление данными рисками.

Как упоминалось ранее, существует множество различных методов обнаружения инсайдерских угроз. Из них видно, что многие из данных атак обнаруживаются с помощью нетехнических средств, таких как мониторинг деструктивного поведения сотрудников.

Исходя из этого, для организаций также важно определить современные программные средства автоматизированного обнаружения, которые могут применять множество методов предотвращения в одном, такие как монито- ринг активности пользователей и анализ поведения пользователей. Например, «Forcepoint insider threat» - это программный инструмент, который может обнаруживать, предотвращать и идентифицировать подозрительные действия, чтобы остановить потерю данных.

Таким образом, важно, чтобы корпорации инвестировали средства как в техническую, так и в нетехническую защиту, чтобы повысить уровень своей безопасности и снизить общий риск.

ОТКРЫТЫЕ ПРОБЛЕМЫ И НАПРАВЛЕНИЯ

\section{НА БУДУЩЕЕ}

Из-за неразрывной связи между поведением человека и сочетанием технических и нетехнических аспектов, обеспечение внутренней безопасности для всех организаций может быть многогранной проблемой. Например, смягчение внутренних угроз может быть сложным из-за таких элементов, как аутсорсинг, глобализация и пандемия COVID-19. Эти элементы могут размыть грань между традиционными инсайдерами и внешними противниками.

Согласно опросу привилегированных пользователей Ponemon Institute, одна из самых больших проблем для компаний заключается в том, что им трудно понять, является ли действие, совершенное инсайдером, угрозой [14]. Инструменты безопасности, которыми они располагают, дают слишком много ложных срабатываний и не дают достаточной информации, поэтому существует необходимость в их совершенствовании или разработке новых инструментов в соответствии с текущими требованиями кибербезопасности.

Далее будут освещены направления борьбы с инсайдерскими угрозами, нацеленными на различные подсистемы организации.

Совместные информационные системы позволяют различным группам пользователей подключаться и сотрудничать над общими задачами, а наибольшая угроза безопасности информационных систем исходит от инсайдеров. Для устранения инсайдерской угрозы в условиях совместной работы был разработан метод обнаружения аномалий и отклонений от ожидаемого поведения. В таких случаях блокчейн, основанный на доверии, может быть хорошим решением для защиты целостности информации, которой обмениваются участники совместной сети, увеличивая их ответственность и предотвращая атаки инсайдеров. 


\section{УГРОЗА НА ПЕРСОНАЛЬНЫХ УСТРОЙ- СTBAX}

Существует теория для противодействия внутренним угрозам на персональных устройствах (ноутбуки и флэш-накопители), включающую четыре метода повышения безопасности персональных устройств:

- разработку программного обеспечения,

- методы обнаружения,

- разработку политики [2].

Современные ученые утверждают, что данная теория является эффективным решением для снижения рисков компании, однако в ней не объясняется, как это используется для выявления злонамеренных инсайдеров.

Кроме того, аналитики безопасности организации нуждаются в оперативных визуальных интерфейсах и интерактивных методах, которые могли бы обнаруживать нарушения безопасности и эффективно обмениваться информацией об угрозах с соответствующим пользователем или органом [11]. Инструмент анализа поведения пользователя из среды «IBM security analytics», может обеспечить тщательный анализ данных.

В целом важно отслеживать индивидуальное использование, доступ к данным и хранение данных на персональных устройствах.

\section{ИНСАЙДЕРЫ В ОБЛАЧНОЙ СРЕДЕ}

Мониторинг моделей вредоносных инсайдеров, имеющих доступ к системе, является заслуживающей внимания проблемой, с которой сталкиваются поставщики услуг в облачной среде. Хотя у облачных пользователей есть много преимуществ, существуют некоторые проблемы с безопасностью. Может быть принята модель обнаружения внутренних угроз, которая использует последовательный анализ правил путем сопоставления входящих событий с профилями пользователей [13]. Такие методы, как алгоритмы машинного обучения и статистическое моделирование, использовались для выявления отклоняющихся пользовательских моделей в работе системы.

В целом, для мониторинга инсайдерской деятельности в «облаке» необходимы элементы управления с обнаружением аномалий на основе правил и анализом криминалистических данных.

\section{КОРПОРАТИВНАЯ ИНСАЙДЕРСКАЯ УГРО-} 3A

Традиционные системы обнаружения вторжений не способны идентифицировать зло- умышленников внутри организации. В этом направлении может быть полезной автоматизированная система, основанная на профилировании структуры, которая способна обнаруживать внутренние угрозы [5]. Такая система включает в себя сведения о действиях каждого пользователя и каждой рабочей роли и использует эти данные для предоставления обширной информации о фактическом поведении пользователя. Отклонение может быть измерено на основе объема отклонений, которые каждый пользователь показывает по нескольким атрибутам по сравнению со своими коллегами.

Управление доступом на основе атрибутов считается перспективной альтернативой традиционным моделям управления доступом.

В целом, технические и поведенческие действия наряду с попытками агрегирования данных позволяют отслеживать обновления данных, а временные изменения следует отслеживать с помощью журналов действий и профилей пользователей.

\section{УГРОЗА В ОРГАНИЗАЦИОННЫХ ИТ-СИ-}

\section{CTEMAX}

Необходимо принять превентивные меры для оценки рисков, а также реактивные методы борьбы с проблемой внутренних угроз. В этом направлении структура, основанная на идентификации, подходит для первоначального анализа требований организационных ИТ-систем. Такая структура предоставляет инженерам по безопасности поддержку в обнаружении внутренних угроз и определяет приоритеты в зависимости от риска, который они представляют для организации.

Также может быть реализован метод обнаружения аномалий одного класса, который измеряет классифицированное сходство между историей пользователя и событиями, записанными во временном окне сеанса пользователя. В качестве альтернативы можно использовать систему, основанную на нейронной сети с долговременной кратковременной памятью (LSTM), которая имитирует системные журналы как естественную структурированную последовательность и фиксирует закономерности нормального поведения пользователей, чтобы отличать нормальное поведение от вредоносных действий [6].

В целом, требуется определение приоритетов рисков, свойств безопасности и уровней чувствительности к активам, методы обнаружения на основе идентификации и сходства. 


\section{ИНСАЙДЕРСКАЯ УГРОЗА В БИЗНЕСЕ ПРЕДПРИЯТИЯ}

Для борьбы с инсайдерской угрозой необходимо сочетание бизнес-процессов предприятия и человеческого фактора, которые их сдерживают. Для использования подходит модель мониторинга процессов, которая объединяет наблюдение на уровне среды выполнения. Входные данные включают психометрические оценки из профилей сотрудников в социальных сетях.

Рассматривается аспект человеческого фактора, а также технические подходы к мониторингу. В качестве контрмер определяется пять подкатегорий защитных решений:

- смягчение последствий и предотвращение,

- обнаружение и оценка угроз,

- передовая практика и руководящие принципы,

- другие практические решения [4].

Многие приложения реального мира отличаются методами сбора данных. Может случиться так, что один вид системы обнаружения, основанной на машинном обучении, может оказаться неэффективным и эффективным для других систем. Кроме того, анализ на основе технологий разделен на две части: на основе хоста и на основе сети.

Источник данных создается в результате непрерывного взаимодействия инсайдера с системой (хостом). Эти взаимодействия состоят из данных уровня приложения, например нажатий клавиш и динамики мыши, системного журнала, журнала системных вызовов и т.д.

Сетевой анализ включает фильтрацию и классификацию данных с использованием машинного обучения, статистического анализа и аналитических методов на основе правил для определения типа угрозы. Все серверы, развер- нутые в сети, отвечают за создание сетевых журналов.

В целом, для обнаружения вредоносного поведения можно использовать сочетание бизнес-процессов предприятия и человеческих факторов. Кроме того, полезно учитывать психометрические оценки из профилей сотрудников в социальных сетях и обученный детектор угроз на основе населения.

\section{ЗАКЛЮЧЕНИЕ}

Угроза инсайдерской информации по-прежнему является реальной проблемой для организаций. В этой работе были исследованы внутренние угрозы и их критичность для организаций. Вредоносные инсайдеры стали серьезной проблемой безопасности для всех предприятий, поскольку инсайдеры могут варьироваться от сотрудников низкого уровня до высокопоставленных сотрудников, обладающих знаниями и доступом к конфиденциальной организационной информации.

Повышение привилегий, атаки с эксфильтрацией и АРТ - это некоторые из многих методов, используемых злоумышленниками. Улучшение защиты может быть достигнуто путем разработки продуманной политики безопасности, а мониторинг деятельности сотрудников имеет важное значение для защиты от вредоносной инсайдерской деятельности.

Таким образом, критическая оценка внутренней угрозы служит для организаций инструментом расширения их знаний о ней. Как упоминалось ранее, необходимо устранять различные формы инсайдерских угроз (обнаруживать и предотвращать любой неправомерный доступ к ресурсам организации), которые нацелены на различные подсистемы организации, такие как уровень устройств, данных, корпоративный и бизнес-уровень.

\section{Библиографический список}

1. Агентство ЕС по информационной безопасности. Отчет о ландшафте угроз. Режим доступа: https://goo. $\mathrm{su} / 8 \mathrm{Hjw}$ (дата обращения 15.10.2021)

2. Борал Л., Дисплей М., Патил С. Противодействие внутренним угрозам в персональных устройствах. США, 2007.

3. Глобальный отчет о стоимости инсайдерских угроз. Обозреватель ИТ. 2020. Режим доступа: https:/goo. $\mathrm{su} / 8 \mathrm{hJW}$ (дата обращения 15.10.2021)

4. Гомоляк И., Тоффалини Ф., Гуарнизо Дж. Понимание инсайдеров и ИТ: Обзор моделирования и контрмер инсайдерской угрозы. 2019.

5. Легг П.А., Бакли О., Голдсмит М. Автоматизированная система обнаружения внутренних угроз с использованием оценки профилей пользователей и ролей. Система IEEE. J. 2017.

6. Лу Дж. Обнаружение внутренних угроз с помощью памяти. Австралия, 2019. 
7. Мур А. П., Шоу Э. Предварительная модель кражи интеллектуальной собственности инсайдером, 2011. Режим доступа: https://goo.su/8Hjх (дата обращения 17.10.2021)

8. Понемон, Л. Стоимость исследования утечки данных: глобальный анализ. Symantec, 2013. Режим доступа: https://goo.su/8hJX (дата обращения 17.10.2021)

9. Скомпрометированный инсайдер и проблемы, которые он создает организациям. Режим доступа: https:// goo.su/8hJx (дата обращения 17.10.2021)

10. Хаггард С., Линдсей Дж.Р. Северная Корея и взлом Sony: экспорт нестабильности через киберпространство, 2015.

11. Хаим Б., Менахем Э., Вольфсталь Ю. Визуализация внутренних угроз: эффективный интерфейс для анализа безопасности. Кипр, 2017.

12. Янссен С. Эксфильтрация данных. Технопедия, 2015. Режим доступа: https://goo.su/8HJх (дата обращения 17.10.2021)

13. Nkosi, L.; Tarwireyi, P.; Adigun, M. O. Insider threat detection model for the cloud. In Proceedings of the 2013 Information Security for South Africa, Johannesburg, South Africa, 14-16 August 2013; pp. 1-8.

14. Privileged User Abuse \& The Insider Threat. Ponemon Institute Research Report. May 2014. Access mode: https:// goo.su/8hjy (accessed 17.10.2021)

15. Trzeciak, R.F. SEI Cyber Minute: Insider Threats. 2017. Access mode: https://goo.su/8hjx (accessed 17.10.2021)

16. What Is an Insider Threat? Access mode: https://goo.su/8hjX (accessed 17.10.2021) 